\title{
Mediation role of perceived social support and burnout on financial satisfaction and turnover intention in primary care providers: a cross-sectional study
}

Huosheng Yan, Lingzhi Sang, Hongzhang Liu, Cancan Li, Zijing Wang, Ren Chen, Hong Ding, Zhi Hu* and Guimei Chen*

\begin{abstract}
Background: Turnover intention is a major cause of reduced team morale and low work efficiency. It hinders work performance and reduces the quality of medical services. This study aimed to investigate the relationship between financial satisfaction and turnover intention and its mediators among primary care providers.

Methods: Multi-stage random cluster sampling was used to select 1241 participants from four counties and three districts in Anhui province, China. Data were collected using a self-administered questionnaire. Turnover intention was assessed with a turnover intention assessment scale. Perceived social support and burnout were measured with the 12-item Perceived Social Support Scale and the Chinese version of the Maslach Burnout Inventory, respectively. Structural equation modeling was used for data analysis.
\end{abstract}

Results: The findings showed high turnover intention among primary care providers (mean score 14.16 \pm 4.337 ), and most providers reported low financial satisfaction (mean score $2.49 \pm 0.990$ ). The mean perceived social support score was $64.93 \pm 13.229$, and only $6.1 \%$ of primary care providers reported no burnout. Compared with participants with high financial satisfaction, those with low financial satisfaction were more likely to report higher turnover intention ( $\beta=-0.216, p<0.001$ ), less perceived social support $(\beta=0.181, p<0.001)$, and more severe burnout $(\beta=$ $-0.123, p<0.05)$. Turnover intention may be related to perceived social support $(\beta=-0.147, p<0.001)$ and burnout $(\beta=0.239, p<0.001)$. Furthermore, the effect of financial satisfaction on turnover intention was significantly mediated by perceived social support $(\beta=-0.027, p<0.001)$ and burnout $(\beta=-0.029, p<0.05)$.

Conclusions: Turnover intention is associated with financial satisfaction, with this association mediated by perceived social support and burnout. A reasonable mechanism needs to be established to improve financial satisfaction and perceived social support and reduce burnout among primary care providers.

Keywords: Perceived social support, Burnout, Financial satisfaction, Turnover intention, Structural equation modeling

* Correspondence: aywghz@ahmu.edu.cn; cgm801@126.com

School of Health Service Management, Anhui Medical University, No.81

Meishan Road, Shushan District, Hefei 230032, China

(c) The Author(s). 2021 Open Access This article is licensed under a Creative Commons Attribution 4.0 International License, which permits use, sharing, adaptation, distribution and reproduction in any medium or format, as long as you give appropriate credit to the original author(s) and the source, provide a link to the Creative Commons licence, and indicate if changes were made. The images or other third party material in this article are included in the article's Creative Commons licence, unless indicated otherwise in a credit line to the material. If material is not included in the article's Creative Commons licence and your intended use is not permitted by statutory regulation or exceeds the permitted use, you will need to obtain permission directly from the copyright holder. To view a copy of this licence, visit http://creativecommons.org/licenses/by/4.0/. The Creative Commons Public Domain Dedication waiver (http://creativecommons.org/publicdomain/zero/1.0/) applies to the data made available in this article, unless otherwise stated in a credit line to the data. 


\section{Background}

Strengthening the primary healthcare system is one of the five key targets of China's healthcare reform, which started in 2009 [1]. This healthcare reform substantially improved access to and affordability of primary healthcare and reduced the disease burden [2]. However, primary healthcare providers face tremendous pressure caused by low levels of training and income. Although the Chinese government has invested many resources in healthcare reform, the reform of the drug system resulted in financial losses for primary care providers [3], however, incentives for primary care providers may be lacking [3]. Over the past decade, the number of primary care providers increased from 3.3 million to 3.8 million because of the continuing increase in demand for health services, but the proportion of primary care providers among all health workers declined from 40.0 to $32.6 \%$ [4]. The shortage of qualified primary care providers remains a critical challenge in healthcare and hinders the further development of the primary care system. Given the long time needed to train qualified health workers, strategies that can be implemented to reduce burnout and turnover intention among primary care providers are key concerns in the current situation.

Financial satisfaction refers to an individual's subjective assessment of his financial status, which is more akin to psychological attributes than objective economic indicators [5]. Financial incentives act as motivation that affects practice behaviors of primary care providers and represents a policy option that can be introduced quickly to induce a behavioral response from primary care providers [6]. However, the same income level may be associated with differences in quality of life across different parts of China because of disparity in regional economic levels. Financial satisfaction is a subjective factor that can eliminate the differences associated with the level of regional economic development. Sufficient financial satisfaction can encourage primary care providers to provide better quality care to patients [7], and providers who provide the highest quality care may be those that are most likely to claim incentive payments [8]. Despite the increase in primary care providers' income in recent years, the salary gap between primary care providers and doctors in general hospitals has widened over the past decade, and primary care providers earn around half as much as general hospital doctors [9]. Higher income satisfaction may reduce turnover intention among primary care providers [10] and reduce the pressure from human resources shortages. However, the primary healthcare system cannot attract younger primary care providers because of the low wages and minimal benefits [2]. Resolving the shortage of doctors working in primary care resulting from financial dissatisfaction has become a problem for policymakers.
Turnover intention is a major challenge in the primary healthcare system and is defined as the possibility of an employee resigning within a certain period [11]. Previous studies showed that the proportion of turnover intention among primary care providers in China ranged from 42.3 to $58.0 \%[12,13]$. This high turnover rate is associated with economic losses. It has been estimated that the recruitment, training, and productivity costs associated with turnover may be more than $5 \%$ of the total annual operating budget of a major medical center [14]. Furthermore, a heavier workload, reduced team morale, and lower work efficiency are unavoidable in the context of high turnover intention, and subsequently hinder work performance [15]. Turnover intention is affected by various factors, such as job satisfaction, work pressure, and burnout [12]. In addition, financial dissatisfaction has frequently been associated with turnover intention. A study involving Chinese primary care providers found low financial satisfaction was associated with turnover intention (odds ratio $[\mathrm{OR}]=0.43, P<$ 0.001 [16]. However, it remains unclear whether other factors mediate the association between financial satisfaction and turnover intention.

Few studies have investigated the mechanism linking financial satisfaction with turnover intention among primary care providers. However, understanding this relationship is essential for developing effective measures to reduce turnover intention. Burnout is a prolonged response to chronic emotional and interpersonal jobrelated stressors and is characterized by emotional exhaustion, depersonalization, and reduced personal accomplishment [17]. A systematic review of the prevalence of burnout found that $67.0 \%$ of physicians had burnout [18]. As well as contributing to poor job performance, productivity decline, and high absence and turnover rates, burnout can exert a negative effect on a person's colleagues [19]. Furthermore, burnout also negatively impacts the quality of sleep, job satisfaction, and coping strategies [20]. Many factors are known to contribute to burnout among primary care providers, including excessive workloads, clerical burdens, workhome conflicts, and financial dissatisfaction [21, 22]. Improving income levels can help reduce burnout. Perceived social support refers to people's beliefs about the amount and quality of support they receive from their relationships and social contacts [23, 24]. Perceived social support can be viewed as individuals' perceptions of available material, emotional, or spiritual support from other individuals or groups of people [25]. A previous study showed that financial satisfaction was associated with higher perceived social support [5]. Perceived social support has also been shown to be a predictor of burnout in Chinese healthcare providers [26]. In addition, perceived social support was found to be a reason for 
turnover intention, and also acted as a partial mediator between job satisfaction, burnout, and turnover intention [27].

To date, most research has addressed the dual relationships between financial satisfaction, turnover intention, perceived social support, and burnout. However, few studies have investigated the mechanism linking financial satisfaction with turnover intention among primary care providers. Therefore, this population-based study aimed to a) explore the associations between financial satisfaction and turnover intention among primary care providers, and b) test the extent to which the association between financial satisfaction and turnover intention may be mediated by perceived social support and burnout. Our findings will contribute to improving work efficiency and alleviating the shortage of primary care providers.

The conceptual model of mediation effect was used in this study [28]. In the mediation model, a relationship between the predictor and outcome variable is explained by mediation variable [28]. In this study, we included perceived social support and burnout as mediating variables. The mediation model hypothesized that perceived social support and burnout would affect by financial satisfaction and influence the association between financial satisfaction and turnover intention.

Guided by the conceptual models, we formulated a hypothesis: perceived social support and burnout serve as two mediators between financial satisfaction and turnover intention.

\section{Methods}

\section{Study design and population}

We conducted a cross-sectional study in four counties and three districts in Anhui province. Anhui province is a major province in the east of China with a large population. Anhui is divided into northern, central, and southern parts because of economic, cultural, and demographic differences. Anhui was the pilot province for the primary healthcare system in China. The primary care providers in this study included medical staff from community health service centers, township health centers, and village clinics.

A Multi-stage random cluster sampling method was used to select a district and a county from southern and central Anhui and one district and two counties from northern Anhui (northern Anhui has a larger population). A questionnaire was conducted with primary care providers, who were selected by cluster sampling method, in selected counties and districts. Each participant completed a self-administered questionnaire independently and anonymously, but research staff was available to address any questions. In each district, the questionnaires were collected by research staff immediately after they were completed by primary care providers. The exclusion criteria for our study were: a) worked for less than 1 year; b) selected the same option for all questions, and c) incomplete answers to the questionnaire. For the present analysis, we included 1214 participants with complete information for the variables analyzed.

Several training sessions were conducted for research staff before the investigation. The study was approved by the research ethics committee, and all participants voluntarily participated in the survey after providing their informed consent.

\section{Measures}

\section{Financial satisfaction}

The independent variable was primary care providers' financial satisfaction. Financial satisfaction was measured using one item that was developed and used in a previous study [29]. Participants were asked: "How satisfied are you with your financial situation?" Response options were: "very satisfied," "satisfied," "somewhat satisfied," "dissatisfied," and "very dissatisfied."

\section{Turnover intention}

The dependent variable was primary care providers' turnover intention. Turnover intention was measured with a modified version of a turnover intention assessment scale, which consisted of six items. The Chinese version of this scale was developed by Mickaeland et al. [30] Responses were on a four-point Likert ranging from $1=$ "never" to $4=$ "always." The total score of the six items was computed as the score for turnover intention, which ranged from 6 to 24; a higher score indicated a stronger turnover intention. The Cronbach's $\alpha$ was 0.881 in this study, indicating that the scale had good internal consistency.

\section{Perceived social support}

The 12-item Perceived Social Support Scale was used to measure perceived social support [31]. This instrument contains 12 items on three subscales: family (items 3,4 , 8 , and 11), friends (items $6,7,9$, and 12), and others (items 1, 2, 5, and 10). The items were rated with a seven-point Likert scale from 1 ("definitely disagree") to 7 ("definitely agree"). The total score is an equally weighted sum of the 12 items, ranging from 12 to 84 . A higher score indicates more perceived social support. The Cronbach's $\alpha$ was 0.940 in this study, which indicated that the questionnaire was applicable.

\section{Burnout}

Burnout was measured using the Chinese version of the Maslach Burnout Inventory [32], which was revised by Li et al. and used in a previous study [33]. This adapted 
version consists of 15 items grouped on three dimensions, each with five items: emotional exhaustion, depersonalization, and reduced personal accomplishment. Responses were on a seven-point scale from 1 (never) to 7 (always), and total scores ranged from 15 to 105. The cut-off scores for emotional exhaustion, depersonalization, and reduced personal accomplishment were 25,11 , and 16 , respectively. According to the cut-off scores, burnout was divided into four grades: no burnout, slight burnout, moderate burnout, and severe burnout. The Cronbach's $\alpha$ for the scale was 0.816 .

\section{Covariables}

To control for potential confounding variables, age (years), gender, and marital status were examined as adjustment variables.

\section{Statistical analysis}

Descriptive statistics were used to summarize the distribution of participant characteristics, the frequency of occurrence of categorical variables (percentages), and the means and standard deviations (SD) of continuous variables.

Structural equation modeling (SEM) is an optimal statistical technique for evaluating a priori models, identifying mediators, and elucidating direct and indirect paths between variables. We used structural equation modeling to investigate the associations between financial satisfaction, turnover intention, and potential mediator mechanisms. Mediation analysis, which is part of structural equation analysis, was used to analyze the relationships between exposure, outcome, and mediating variables. In Fig. 1, financial satisfaction was treated as an exogenous variable, estimating two latent variables (perceived social support and burnout).

The data in this study follows a multivariate normal distribution. Maximum likelihood was used to estimate model parameters. The model fit was estimated by: a) ratio of chi-square value to degrees of freedom $\left(x^{2} / \mathrm{df}\right)$ $\leq 3$; b) comparative fit index $(\mathrm{CFI}) \geq 0.90$; c) TuckerLewis index (TLI) $>0.9$ d) standardized root mean square residual (SRMR) < 0.05 ; and e) root mean square error of approximation (RMSEA) < 0.05 [34]. Descriptive analyses were performed using SPSS 25.0 Statistics for Windows, version 25.0 (IBM Corp, Armonk, NY, USA). Mplus, version 7.4 (Muthen \& Muthen, Los Angeles, CA, USA) was used for the structural equation modeling.

\section{Results}

Characteristics of study participants

The mean age for the 1214 participants was 40.26 (SD = 8.614 ) years, $55.0 \%$ were women, and $91.3 \%$ were

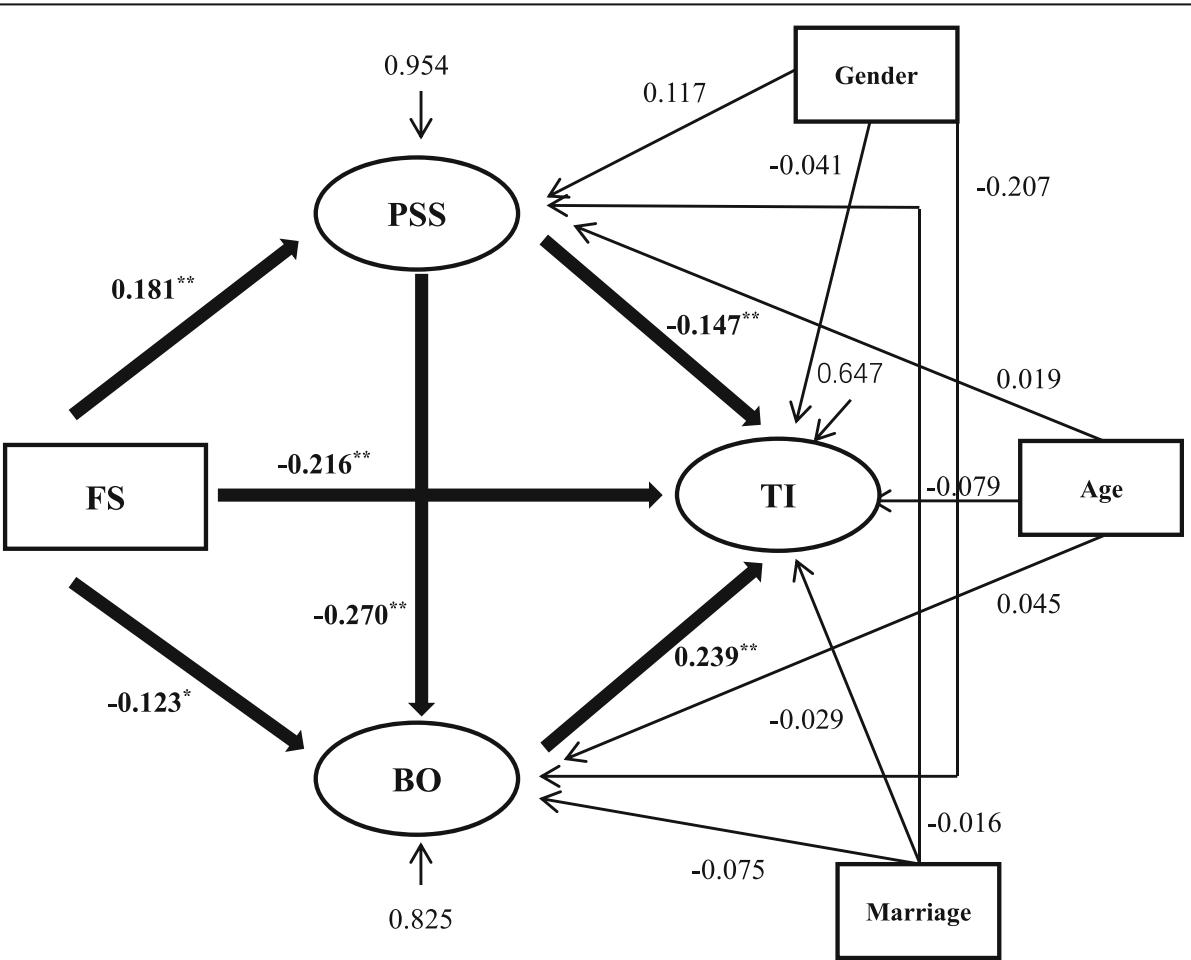

Fig. 1 Results of the structural equation model. ${ }^{*} p<0.001,{ }^{*} p<0.05$; Adjusted for age, gender, and marital status. IS: financial satisfaction, PSS: perceived social support, BO: burnout, Tl: turnover intention 
married (6.8\% were unmarried, $1.3 \%$ were divorced, and $0.7 \%$ were widowed).

We found that $6.1 \%$ of participants had no burnout, $45.0 \%$ had slight burnout, $37.6 \%$ had moderate burnout, and $11.3 \%$ had severe burnout. The mean financial satisfaction score was $2.49(\mathrm{SD}=0.990)$ out of a possible total score of 5 . The mean score for turnover intention was $14.16(\mathrm{SD}=4.337)$, indicating that participants had a moderate turnover intention. Furthermore, the mean perceived social support score was $64.93(\mathrm{SD}=13.229)$ (Table 1).

\section{Structural equation modeling}

Models were built to estimate the relationships between financial satisfaction, turnover intention, perceived social support, and burnout (Fig. 1). The model fit indices and standardized direct effects among four variables and indirect effects of two mediation variables are shown in Tables 2 and 3, after adjusting gender, marital status, occupation, length of service and types of primary health care facilities. The model fit indices were evaluated as: $X^{2} / \mathrm{df}=2.909, \quad$ CFI $=0.978, \quad$ TLI $=0.970, \quad$ SRMR $=0.039$, RMSEA $=0.040$ and $90 \%$ confidence interval $(\mathrm{CI})=0.033$ to 0.046 , which showed the model had good fit.

\section{Relationships among variables}

In the SEM, financial satisfaction had a significant direct effect on turnover intention $(\beta=-0.216,95 \% \mathrm{CI}-0.279$ to -0.152 ); participants with higher financial satisfaction were more likely to report low turnover intention. Financial satisfaction was significantly associated with

Table 1 Participants' characteristics at baseline

\begin{tabular}{lll}
\hline Variables & Mean (SD) & $\mathbf{n}(\%)$ \\
\hline Age & $40.26(8.614)$ & \\
Gender & & \\
$\quad$ Male & & $668(45.0)$ \\
$\quad$ Female & & \\
Marital status & & $1108(91.0)$ \\
$\quad$ Married & & $82(6.8)$ \\
$\quad$ Unmarried & $16(1.3)$ \\
$\quad$ Divorced & $8(0.7)$ \\
$\quad$ Widowed & \\
Financial satisfaction & & \\
Turnover intention & & \\
Perceived social support & $6.49(0.990)$ & \\
Burnout & $14.16(4.337)$ & $74(6.1)$ \\
$\quad$ No & & $546(45.0)$ \\
Slight & & $457(37.6)$ \\
Moderate & & $137(11.3)$ \\
Severe & &
\end{tabular}

Table 2 Model fit indices

\begin{tabular}{ll}
\hline Model Fit & Home \\
\hline$X^{2} / d f$ & 2.909 \\
CFI & 0.978 \\
TLI & 0.970 \\
SRMR & 0.039 \\
RMSEA & $0.040(0.033,0.046)$ \\
\hline
\end{tabular}

two mediating variables. Higher financial satisfaction was associated with a decreased likelihood of having burnout ( $\beta=-0.123,95 \%$ CI -0.210 to -0.017$)$ compared with low financial satisfaction. In terms of perceived social support, financial satisfaction often reflected higher perceived social support $(\beta=0.181,95 \%$ CI $0.125-0.234$ ) for primary care providers.

Associations were also found between turnover intention and the two mediating variables. A higher perceived social support score was associated with lower turnover intention $(\beta=-0.147,95 \% \mathrm{CI}-0.217$ to 0.080 ). In addition, turnover intention was significantly influenced by burnout $(\beta=0.239,95 \%$ CI 0.140 to 0.328 ), and participants with higher burnout were more likely to report higher turnout intention.

Furthermore, the association between two mediating variables (perceived social support and burnout) was significant, with low perceived social support indicating higher burnout ( $\beta=-0.270,95 \%$ CI -0.355 to -0.178 ). The direct and indirect effects were significant before and after the covariates were added into the model. More details are shown in Table 2.

\section{Mediation role of perceived social support and Burnout}

The multi-serial mediator model demonstrated that perceived social support played a potential mediating role in the association between financial satisfaction and turnover intention $(\beta=-0.027,95 \% \mathrm{CI}-0.042$ to 0.013). Burnout also displayed a mediator effect in the relationship between financial satisfaction and turnover intention $(\beta=-0.029,95 \% \mathrm{CI}-0.059$ to -0.003$)$. Besides, the indirect effect on financial satisfaction and turnover intention, mediated by perceived social support to burnout, was significant $(\beta=-0.012,95 \%$ CI -0.019 to -0.005$)$. Overall, the three indirect pathways between financial satisfaction and turnover intention were not greater than the direct pathway. In terms of three potential mediating pathways, burnout was greater than the other two pathways.

\section{Discussion}

This study presented critical information regarding the current profile of financial satisfaction, turnover intention, perceived social support, and burnout and their relationships among primary care providers in 
Table 3 Standardized direct and indirect effects

\begin{tabular}{|c|c|}
\hline Variables & Standardized coefficient \\
\hline \multicolumn{2}{|l|}{ Direct effects } \\
\hline \multicolumn{2}{|l|}{ Perceived social support } \\
\hline Financial satisfaction & $0.181(0.125,0.234) * *$ \\
\hline Burnout & $-0.123(-0.210,-0.017) *$ \\
\hline Turnover intention & $-0.216(-0.279,-0.152) * *$ \\
\hline \multicolumn{2}{|l|}{ Burnout } \\
\hline Financial satisfaction & $-0.270(-0.355,-0.178) * *$ \\
\hline Turnover intention & $-0.147(-0.217,-0.080) * *$ \\
\hline \multicolumn{2}{|l|}{ Turnover intention } \\
\hline Financial satisfaction & $0.239(0.140,0.328) * *$ \\
\hline \multicolumn{2}{|l|}{ Indirect effects } \\
\hline Financial satisfaction -- > Perceived social support -- > Turnover intention & $-0.027(-0.042,-0.013) * *$ \\
\hline Financial satisfaction -- > Burnout -- > Turnover intention & $-0.029(-0.059,-0.003) *$ \\
\hline Financial satisfaction -- > Perceived social support -- > Burnout -- > Turnover intention & $-0.012(-0.019,-0.005) * *$ \\
\hline Total Indirect & $-0.068(-0.100,-0.037) * *$ \\
\hline
\end{tabular}

${ }^{* *} p<0.001,{ }^{*} p<0.05$; Adjusted for age, gender, and marital status

China. Our results showed that financial satisfaction was strongly related to turnover intention, and individuals who were dissatisfied with their financial situation had a higher risk for turnover intention However, this correlation occurred through both direct and indirect effects. Financial satisfaction had a significant indirect effect on turnover intention mediated by perceived social support and burnout. Moreover, the pathway from perceived social support to burnout played a mediating role between financial satisfaction and turnover intention.

Financial satisfaction was measured using one item in this study for the following reasons. First, one item to measure financial satisfaction has been used and its reliability has been confirmed from previous studies [27, 35-37]. In this study, to make our results more comparable with these studies, we also used one item to collect financial satisfaction data. Second, one item is more in accord with the actual situation in China. The income structure of primary care providers in China is complex, which consists of basic salary, performance salary, bonus, operational income (e.g., operate personal clinics and pharmacies), and off-the-books income. Financial satisfaction is significantly influenced by operational income and off-the-books income. However, this part of financial satisfaction is difficult to obtain due to: a) respondents refuse to answer because they do not consider this part of the income as formal earnings from work; b) respondents do not want these incomes to be known by investigators or other respondents at the same place (such as this income is illegal).

The results showed that primary care providers were generally dissatisfied with their financial situation. This finding was consistent with a previous study that found primary care providers were the least satisfied with their income [38]. Since 1980, primary care providers in China have been able to charge a $15 \%$ markup on drug sales, but this was abolished in 2017 because of overprescribing of drugs. The government increased its subsidy for primary healthcare institutions, but this policy substantially reduced the incomes of primary care providers [2]. The mean score for turnover intention was 14.16, which was similar to previous results for general practitioners [39]. The possible interpretation for the high-level turnover intention among Chinese primary care providers is their heavy workload, low-income level, and few professional development opportunities [16]. Moreover, $11.3 \%$ of participants reported severe burnout, which was higher than that reported among Chinese primary care doctors [40] and primary care providers in the US [41]. The mean score for perceived social support in this study was 64.93 , which was lower than reported in a previous study involving Chinese physicians [27].

To our knowledge, this is the first population-based study among Chinese primary care providers that investigated the relationship of financial satisfaction and turnover intention as well as the mediating roles of perceived social support and burnout. Prior studies observed correlations between financial satisfaction and turnover intention [10, 39]. However, those studies used different participant groups (e.g., specialist physicians) or analysis methods (e.g., traditional regressions and correlations). Although those studies differed from ours in terms of specific details, the results regarding the negative relationship between financial satisfaction and turnover 
intention were consistent, which confirms the results of our study.

This study found that financial satisfaction was associated with an increased likelihood of high perceived social support among primary care providers. A study conducted among primary healthcare patients in Brazil suggested that people with a high income were more likely to receive more perceived social support than those with a low income [42]. The workloads of primary care providers have surged since the introduction of the basic public health services program [43]. Furthermore, compared with workers with a low income, those with a high income may be able to get more support from coworkers [44]. However, income levels and workloads appear to be mismatched. Financial dissatisfaction may also reduce the desire for social intercourse and increase pressure in family life. Support from social networks may therefore be reduced by financial dissatisfaction and lack of communication. We found a correlation between low perceived social support and high risk for turnover intention, which was consistent with a previous survey of Chinese specialist physicians and emergency room nurses $[27,45]$. Social relationships are established by primary care providers in daily life and also at work (e.g., physician-nurse, physician-leadership, and physician patient relationships). Primary care providers can also receive encouragement and support from their daily life networks (e.g., family and friends) or work networks (e.g., leaders and colleagues) when faced with increased workloads. These factors may explain the mediating role of perceived social support in financial satisfaction and turnover intention observed in this study. Financial dissatisfaction may lead to decreased perceived social support from family, friends, and colleagues because of lack of communication and increased life pressure, and turnover intention increases when there is a lack of perceived social support.

Financial dissatisfaction means a higher level of burnout for primary care providers; although this has not been confirmed in primary care providers, it has been described in previous studies conducted among Korean doctors [10] and Chinese nurses [46]. Moreover, an association between burnout and turnover intention was observed in this study, which was consistent with earlier findings for physicians in the United States [47]. Factors predicting burnout include low reward, excessive workload, low organizational status, and low support [48]. Medical and basic public health services provided by primary care providers that resulted in excessive workloads did not increase their income. Furthermore, there is no professional rank promotion system for primary care providers in China, which means it is difficult for them to gain a higher organizational status [49]. This may explain the associations between financial satisfaction, burnout, and turnover intention in primary care providers in this study. A mediating role of burnout between financial satisfaction and turnover intention was found in our study. Financial satisfaction was a predictor factor of burnout, and low financial satisfaction was reflected in a high level of burnout; that is, the higher level of burnout, the greater risk for turnover intention. In addition, we found a multi-serial mediation role of burnout through perceived social support between financial satisfaction and turnover intention. Financial dissatisfaction may reduce perceived social support through decreased social intercourse and increased family life pressure. Decreases in perceived social support, especially support from colleagues, may increase the risk for burnout, thereby leading to increased turnover intention.

We selected age, gender, and marital status as covariables to control potential confounding variables in the SEM. The direct and indirect effects were significant before and after the covariates were added to the model.

The strengths of this research include the use of SEM, which is an analytical method suitable for evaluation and measurement that can eliminate measurement errors for variables that are difficult to measure, such as perceived social support, burnout, and turnover intention. This study also showed a direct effect among four study variables and the mediation linking financial satisfaction with turnover intention, which is the first time this has been shown among primary care providers.

This study had several limitations. First, the measurements of financial satisfaction, turnover intention, perceived social support, and burnout were obtained using self-administered questionnaires, meaning self-report bias might have impacted the results. Second, this study was a cross-sectional study, and the interpretation of causal inferences on the results is limited. Third, the lack of work-related covariables might influence the reliability of our results. Finally, the sample was selected from one province, so the extrapolation of conclusions to the national level could be challenged. These limitations need to be addressed in further research.

\section{Conclusion}

Our study indicates that financial dissatisfaction, low perceived social support, and burnout can aggravate turnover intention. Furthermore, perceived social support and burnout mediate the association between financial dissatisfaction and turnover intention. Our study offers an exploration of possible pathways between financial dissatisfaction and turnover intention and may have implications for reducing turnover intention among primary care providers. Ultimately, our research findings may help to alleviate the shortage of primary care providers and improve the quality of medical services. First, 
remuneration mechanisms need to be established to increase the income of primary care providers; for example, income could be determined by workload or professional level. Second, suitable professional promotion and organizational management systems need to be established to encourage retention among primary care providers. Finally, measures to improve perceived social support and reduce burnout are needed, such as decreased workloads and improved organizational status for primary care providers.

\section{Abbreviation}

SEM: Structural equation modeling.

\section{Acknowledgements}

The authors are grateful to all participants who voluntarily agreed to complete the survey.

\section{Authors' contributions}

Study concept and design: GC and $\mathrm{ZH}$; acquisition of data: $\mathrm{LS}$ and $\mathrm{HL}$; analysis and interpretation of data: $\mathrm{HY}, \mathrm{CL}$ and $\mathrm{ZW}$; Drafting of the manuscript: $\mathrm{HY}$; Critical revision of the manuscript for important intellectual content: GC, ZH, RC and HD. All authors have reviewed and approved the final manuscript for submission.

\section{Funding}

This study was funded by the Anhui Health Development Strategy Research Center (No. 0503011216) and Major Project of Humanities and Social Sciences Research in Anhui Higher Education Institutions (No. SK2017A0169). The views expressed are those of the authors. The funder has no role in the conduct of the research or the decision to submit this report.

\section{Availability of data and materials}

The datasets used and/or analysed during the current study are available from the corresponding author on reasonable request.

\section{Declarations}

\section{Ethics approval and consent to participate}

The study was approved by the Ethical Committee of Anhui Medical University (AMUREC:20170260). Written informed consent was provided by all participants before answering the questionnaire, including consent for deidentified data to be used in publications arising from the research.

\section{Consent for publication}

Not applicable.

\section{Competing interests}

The authors declare that they have no competing interests.

Received: 14 October 2020 Accepted: 10 March 2021

Published online: 19 March 2021

\section{References}

1. Chen Z. Launch of the health-care reform plan in China. Lancet. 2009; 373(9672):1322-4.

2. Li X, Lu J, Hu S, Cheng KK, De Maeseneer J, Meng Q, et al. The primary health-care system in China. Lancet. 2017;390(10112):2584-94.

3. Yip WC, Hsiao WC, Chen W, Hu S, Ma J, Maynard A. Early appraisal of China's huge and complex health-care reforms. Lancet. 2012;379(9818): 833-42.

4. National Health Commission of China. China Health Statistical Yearbook 2018. Beijing: Peking Union Medical College Press; 2018.

5. Ng W, Diener E. What matters to the rich and the poor? Subjective wellbeing, financial satisfaction, and postmaterialist needs across the world. J Pers Soc Psychol. 2014;107(2):326-38.

6. Yip WC, Hsiao W, Meng Q, Chen W, Sun X. Realignment of incentives for health-care providers in China. Lancet. 2010;375(9720):1120-30.
7. Hung LM, Shi L, Wang H, Nie X, Meng Q. Chinese primary care providers and motivating factors on performance. Fam Pract. 2013;30(5):576-86.

8. Kiran T, Victor JC, Kopp A, Shah BR, Glazier RH. The relationship between financial incentives and quality of diabetes care in Ontario. Canada Diab Care. 2012;35(5):1038-46

9. Ma X, Wang H, Yang L, Shi L, Liu X. Realigning the incentive system for China's primary healthcare providers. Bmj. 2019;365:12406.

10. Oh S, Kim H. Turnover intention and its related factors of employed doctors in Korea. Int J Environ Res Public Health. 2019;16:14.

11. Chao MC, Jou RC, Liao CC, Kuo CW. Workplace stress, job satisfaction, job performance, and turnover intention of health care workers in rural Taiwan. Asia Pac J Public Health. 2015;27(2):Np1827-36.

12. Wen $T$, Zhang $Y$, Wang $X$, Tang G. Factors influencing turnover intention among primary care doctors: a cross-sectional study in Chongqing. China Hum Resour Health. 2018;16(1):10.

13. Zhang M, Yan F, Wang W, Li G. Is the effect of person-organisation fit on turnover intention mediated by job satisfaction? A survey of community health workers in China. BMJ Open. 2017;7(2):e013872.

14. Waldman JD, Kelly F, Arora S, Smith HL. The shocking cost of turnover in health care. Health Care Manag Rev. 2010;35(3):206-11.

15. Tzeng HM. The influence of nurses' working motivation and job satisfaction on intention to quit: an empirical investigation in Taiwan. Int J Nurs Stud. 2002;39(8):867-78.

16. Gan Y, Jiang H, Li L, Yang Y, Wang C, Liu J, et al. A national survey of turnover intention among general practitioners in China. Int J Health Plann Manag. 2020;35(2):482-93.

17. Maslach C, Schaufeli WB, Leiter MP. Job burnout. Annu Rev Psychol. 2001;52: 397-422.

18. Rotenstein LS, Torre M, Ramos MA, Rosales RC, Guille C, Sen S, et al. Prevalence of Burnout among physicians: a systematic review. Jama. 2018; 320(11):1131-50.

19. Panagioti M, Geraghty K, Johnson J, Zhou A, Panagopoulou E, ChewGraham C, et al. Association between physician Burnout and patient safety, professionalism, and patient satisfaction: a systematic review and metaanalysis. JAMA Intern Med. 2018;178(10):1317-30.

20. Qiao Z, Chen L, Chen M, Guan X, Wang L, Jiao Y, et al. Prevalence and factors associated with occupational burnout among HIV/AIDS healthcare workers in China: a cross-sectional study. BMC Public Health. 2016;16:335.

21. West CP, Dyrbye LN, Shanafelt TD. Physician burnout: contributors, consequences and solutions. J Intern Med. 2018;283(6):516-29.

22. Pulcrano M, Evans SR, Sosin M. Quality of life and Burnout rates across surgical specialties: a systematic review. JAMA Surg. 2016;151(10):970-8.

23. Hupcey JE. Clarifying the social support theory-research linkage. J Adv Nurs. 1998:27(6):1231-41.

24. Dour HJ, Wiley JF, Roy-Byrne P, Stein MB, Sullivan G, Sherbourne CD, et al. Perceived social support mediates anxiety and depressive symptom changes following primary care intervention. Depress Anxiety. 2014;31(5): 436-42.

25. Sarason BR, Sarason IG, Pierce GR. Social support: an interactional view; 1990.

26. Liu Y, Aungsuroch Y. Work stress, perceived social support, self-efficacy and burnout among Chinese registered nurses. J Nurs Manag. 2019;27(7):1445-53.

27. Duan $X, N i X$, Shi $L$, Zhang $L, Y e ~ Y, M u ~ H$, et al. The impact of workplace violence on job satisfaction, job burnout, and turnover intention: the mediating role of social support. Health Qual Life Outcomes. 2019;17(1):93.

28. Baron RM, Kenny DA. The moderator-mediator variable distinction in social psychological research: conceptual, strategic, and statistical considerations. J Pers Soc Psychol. 1986;51(6):1173-82.

29. Rautio N, Kautiainen H, Koponen H, Mäntyselkä P, Timonen M, Niskanen L, et al. Financial satisfaction and its relationship to depressive symptoms in middle-aged and older adults: results from the FIN-D2D survey. Int I Soc Psychiatry. 2013;59(3):239-46.

30. Michaels CE, Spector PE. Causes of employee turnover: a test of the Mobley, Griffeth, hand, and Meglino model. J Appl Psychol. 1982;67(1):53.

31. Dahlem NW, Zimet GD, Walker RR. The multidimensional scale of perceived social support: a confirmation study. J Clin Psychol. 1991;47(6):756-61.

32. Maslach C, Jackson S, Leiter M. The Maslach Burnout Inventory Manual; 1997. p. 191-218.

33. Zhou J, Yang Y, Qiu X, Yang X, Pan H, Ban B, et al. Relationship between anxiety and Burnout among Chinese physicians: a moderated mediation model. PLoS One. 2016;11(8):e0157013. 
34. Lt H, Bentler PM. Cutoff criteria for fit indexes in covariance structure analysis: conventional criteria versus new alternatives. Struct Equ Model. 1999;6(1):1-55

35. Diener $\mathrm{E}$, Diener M. Cross-cultural correlates of life satisfaction and selfesteem. J Pers Soc Psychol. 1995;68(4):653-63.

36. Pu C, Tang GJ, Huang N, Chou YJ. Predictive power of self-rated health for subsequent mortality risk during old age: analysis of data from a nationally representative survey of elderly adults in Taiwan. J Epidemiol. 2011;21(4): 278-84.

37. Ng W, Russell Kua WS, Kang SH. The relative importance of personality, financial satisfaction, and autonomy for different subjective well-being facets. Aust J Psychol. 2019;153(7):680-700.

38. Wang $H$, Jin $Y$, Wang D, Zhao $S$, Sang $X$, Yuan B. Job satisfaction, burnout, and turnover intention among primary care providers in rural China: results from structural equation modeling. BMC Fam Pract. 2020;21(1):12

39. Gan Y, Gong Y, Chen Y, Cao S, Li L, Zhou Y, et al. Turnover intention and related factors among general practitioners in Hubei, China: a crosssectional study. BMC Fam Pract. 2018;19(1):74.

40. Gan Y, Jiang H, Li L, Yang Y, Wang C, Liu J, et al. Prevalence of burnout and associated factors among general practitioners in Hubei, China: a crosssectional study. BMC Public Health. 2019;19(1):1607

41. Edwards ST, Marino M, Balasubramanian BA, Solberg LI, Valenzuela S, Springer R, et al. Burnout among physicians, advanced practice clinicians and staff in smaller primary care practices. J Gen Intern Med. 2018;33(12): 2138-46.

42. Azevedo C, Pessalacia JDR, Mata L, Zoboli E, Pereira MDG. Interface between social support, quality of life and depression in users eligible for palliative care. Rev Esc Enferm USP. 2017:51:e03245.

43. Sun Y, Luo Z, Fang P. Factors influencing the turnover intention of Chinese community health service workers based on the investigation results of five provinces. J Community Health. 2013;38(6):1058-66.

44. Hu SH, Yu YM, Chang WY, Lin YK. Social support and factors associated with self-efficacy among acute-care nurse practitioners. J Clin Nurs. 2018;27(3-4): 876-82

45. Bruyneel L, Thoelen T, Adriaenssens J, Sermeus W. Emergency room nurses' pathway to turnover intention: a moderated serial mediation analysis. J Adv Nurs. 2017;73(4):930-42.

46. Wang QQ, Lv WJ, Qian RL, Zhang YH. Job burnout and quality of working life among Chinese nurses: a cross-sectional study. J Nurs Manag. 2019; 27(8):1835-44

47. Willard-Grace R, Knox M, Huang B, Hammer H, Kivlahan C, Burnout GK Health care workforce turnover. Ann Fam Med. 2019;17(1):36-41.

48. Lo D, Wu F, Chan M, Chu R, Li D. A systematic review of burnout among doctors in China: a cultural perspective. Asia Pac Fam Med. 2018;17:3.

49. Zhang M, Yang R, Wang W, Gillespie J, Clarke S, Yan F. Job satisfaction of urban community health workers after the 2009 healthcare reform in China: a systematic review. Int J Qual Health Care. 2016;28(1):14-21.

\section{Publisher's Note}

Springer Nature remains neutral with regard to jurisdictional claims in published maps and institutional affiliations.

Ready to submit your research? Choose BMC and benefit from:

- fast, convenient online submission

- thorough peer review by experienced researchers in your field

- rapid publication on acceptance

- support for research data, including large and complex data types

- gold Open Access which fosters wider collaboration and increased citations

- maximum visibility for your research: over $100 \mathrm{M}$ website views per year

At $\mathrm{BMC}$, research is always in progress.

Learn more biomedcentral.com/submissions 